\title{
Seasonality of Influenza in the Tropics: A Distinct Pattern in Northeastern Brazil
}

\author{
Fernanda E. A. Moura,* Anne C. B. Perdigão, and Marilda M. Siqueira \\ Laboratório de Virologia, Departamento de Patologia e Medicina Legal, Universidade Federal do Ceará, Fortaleza, Ceará, Brazil; Laboratório de \\ Vírus Respiratórios e Sarampo, Instituto Oswaldo Cruz (IOC/FIOCRUZ), Rio de Janeiro, Brazil
}

\begin{abstract}
Influenza epidemics occur worldwide annually. The incidence of influenza shows a seasonal pattern in temperate areas, but little is known about influenza seasonality in tropical regions. The objective of this study was to determine the prevalence and the seasonal pattern of influenza infections in children living in the city of Fortaleza in northeastern Brazil. An indirect immunofluorescence assay was performed on nasopharyngeal aspirates collected from children attending in ambulatories, emergency rooms, and wards of the Hospital Infantil Albert Sabin with suspicion of acute respiratory infection during 7 consecutive years (2001-2007). Influenza viruses were detected in 6.3\% (234/3,708) of specimens. Laboratory-based surveillance data showed a clear annual epidemic cycle of influenza, with a peak usually occurring in the rainy periods. In Fortaleza, flu infections occurred at a low level throughout the year but exhibit a marked seasonal increase during the rainy season.
\end{abstract}

\section{INTRODUCTION}

Among several respiratory viruses, influenza represents the greatest threat to the public, because of the possibility of seasonal epidemics or even pandemic. Information on influenza epidemiology and seasonality is important in planning prevention and treatment strategies. The patterns of influenza seasons are less apparent in the tropics than in temperate regions, where they are associated with the winter period. ${ }^{1}$ In tropical areas, three patterns have been observed: 1 ) infections occur all year round with peaks related to the rainy seasons, as seen in India, Senegal, and Indonesia; 2) infections occur all year round with biannual peaks associated to rainy season and winter months; and 3) infections occur without a clear seasonality. ${ }^{2-8}$

Epidemiologic data on influenza are scarce and inaccurate in Brazil and come mostly from short-term studies. ${ }^{9-16}$ This study was conducted to determine the prevalence and the seasonal pattern of influenza infections in children living in city of Fortaleza in northeastern Brazil.

\section{MATERIALS AND METHODS}

Study area and site. Fortaleza, the capital of the state of Ceará, northeastern Brazil, is a city of 2,250,000 inhabitants at sea level, $4^{\circ}$ south of the Equator, with a tropical climate characterized by two distinct seasons: the rainy season, which occurs in the first half of each year, usually from January and May, and a dry season during the rest of the year. The climate has a constant high relative humidity (>70\%), and the temperature varies little throughout the year. During this study, the lowest and highest daytime temperatures in Fortaleza were $21.1^{\circ} \mathrm{C}$ and $33.9^{\circ} \mathrm{C}$, respectively.

The center for the study was the Hospital Infantil Albert Sabin (HIAS), a public teaching hospital that provides care to children from low-income families in Fortaleza. This study was conducted from January 2001 through December 2007.

Population. Children with acute respiratory infections (ARIs) were identified when their parents requested medical attention at the HIAS. Nasopharyngeal aspirate (NPA) was collected from each child, 1 month to 16 years of age,

\footnotetext{
* Address correspondence to Fernanda E. A. Moura, R. Monsenhor Furtado s/n, Rodolfo Teófilo, Fortaleza-CE 60441-750, Brazil. E-mail: fernandaedna@terra.com.br
}

who came to the HIAS with complaints of ARI within 7 days of onset. Samples were collected 5 days/wk from Monday to Friday by a medical student who remained in the hospital for 4 hours each collection day for this purpose. Parents or caretakers gave their written informed consent allowing the inclusion of children in the study. The Research Ethics Committee of the HIAS approved this study.

Virus antigen detection. Samples were processed and screened for influenza A and B, adenovirus, respiratory syncytial virus (RSV), and parainfluenza viruses 1,2, and 3, using an indirect immunofluorescence assay (IFA) that was carried out using the Respiratory Panel I Viral Screening and Identification (Chemicon International, Temucula, CA), following the manufacturer's instructions, as described previously. ${ }^{17}$

Definitions of influenza and rainy seasons. The influenza seasons were defined as the period of time during which the number of cases of influenza were $\geq 10 \%$ of the total of positive samples for influenza. The rainy seasons were defined as the group of months that contain $70 \%$ or more of the year's rain volume. The beginning of the rainy season was defined as the month in which $10 \%$ or more of the year's total rain volume occurs.

Statistical methods. Descriptive statistics (mean, SD, Student $t$-test) were used for univariate analysis. Comparisons were carried out using the Fisher exact test and Pearson $\chi^{2}$ for categorical variables. All $P$ values were considered significant if $\leq 0.05$. The Spearman correlation test was used to correlate the total number of ARI cases, the number of influenza cases, and monthly rainfall.

\section{RESULTS}

From January 2001 to December 2007, a total of 3,708 samples were collected from children with ARIs who were enrolled in the study. An average of 10 samples was collected each week, with a maximum of 20 NPAs each week and a minimum of 2 NPAs during the long holidays (Carnival, Easter, and Christmas). A total of 1,089 samples (29.3\%) were positive for at least one of the viruses screened for, and 234 were found to be positive for influenza (type $A=209,89.3 \%$; type $\mathrm{B}=25,10.7 \%$ ). Influenza types $\mathrm{A}$ and $\mathrm{B}$ circulated simultaneously in most seasons, but the former predominated in all seasons and was the only type circulating in 2006. Between analyzed viruses, influenza was the second-most frequent virus detected after RSV in all years of study. 
Most of the patients with influenza were outpatients $(88.8 \%)$ presenting infections of the upper airways $(61.5 \%)$. The median age of patients with influenza was 34 months (range, 1 month to 15 years). The sex distribution was $51.3 \%$ $(N=120)$ male and $48.7 \%$ (114) female.

Influenza seasons in Fortaleza lasted from 1 to 4 months. The earliest cases were observed in January $(2004,2005)$, February (2002), March (2001), and April (2003, 2006, 2007), and the last cases in March (2004), April (2003, 2006), May (2002, 2005), June (2001), or July (2007). In 2003, all influenza cases were detected in April. Influenza seasons occurred during the first half of each year, when $94.4 \%$ of the confirmed cases were detected. Of this period, cases were detected only in July (2004, 2006, and 2007) or September (2001, 2004, 2005, 2006). The peak of influenza seasons occurred from February to May, when $88.8 \%$ of all cases occurred. The monthly distribution of ARI caused by influenza viruses is shown in Figure 1.

The results of this study show a statistically significant association of the occurrence of ARI and influenza seasons with the rainy season $(P<0.0001$; Figure 2$)$.

\section{DISCUSSION}

This study originates from extensive respiratory virus surveillance in children attending Albert Sabin Children's Hospital. Given that there is a general lack of information regarding the occurrence of viral respiratory infections in Fortaleza, this study provided the first information about local circulation of some viruses. ${ }^{17,18}$ Hitherto, nothing had been produced concerning influenza. The inclusion of cases of upper and lower respiratory infection, and not only those characterized as "flulike," allowed us to better study viral infections, eliminating some possible bias in the selection of patients. The collection of samples followed the spontaneous demand of patients with ARIs attending HIAS. There were days that it was not possible to take samples from all the ARI cases, because of the excess number of patients with ARIs, and there were days that students returned without samples because of no ARI cases. It was possible to observe that, during the first half of the year, in the rainy period, there was a considerable increase in the number of consultations regarding ARIs, not attributed only to influenza. In agreement with previous data, this study showed that RSV plays a crucial part in the increase of ARIs during this period. ${ }^{17}$

Our results showed that, in this area of the northeast region, a typical tropical region, influenza seasons occur regularly during the first half of each year in strong association with the rainy seasons, which is not in agreement with data from several studies that showed a less evident seasonal pattern of influenza in tropical and subtropical regions. ${ }^{1}$

There is evidence that the seasonal patterns of a number of respiratory viruses, especially influenza and $\mathrm{RSV}$, are related to environmental conditions. In temperate climates, flu infections exist at a low level throughout the year but exhibit a marked seasonal increase during the winter months. ${ }^{19}$ In Fortaleza, the peak periods of rainy seasons occurs from February to June, as observed here. Inside of this period, $93 \%$ of cases of influenza in this study were observed. Rainy periods seem to be correlated with the occurrence of influenza in this area of the northeast region in a similar way that low temperatures are associated to influenza seasons in temperate regions of Brazil. $^{10,15,16}$

A regular pattern of one epidemic period of influenza by year observed during the 7 years of this study contrasts with seasonality of influenza in other tropical areas, where influenza can occur throughout the year or in two peaks by year; this former pattern has been reported in studies from Singapore (tropical climate) and Hannoi, Vietnam (subtropical climate). In these countries, peaks of influenza circulation are related to the rainy season and winter months. ${ }^{3,6}$ In Fortaleza, flu infections occurred at a low level throughout the year but exhibited a marked seasonal increase during the rainy season. Out of the rainy season, influenza cases were detected only in July or September. During the study, there were variations between the occurrence of the rainy season and the status of the influenza season. In fact, most of the years studied presented the highest number of influenza cases after the beginning of the rainy season. For example, in 2003 and $2005,100 \%$ and $74 \%$ of the influenza cases, respectively, were observed during the fourth month of the rainy season. In 2002, 2004, 2006, and 2007, the influenza season occurred 1 month after the beginning of the rainy season. The extension of the influenza season did not correspond to the one of
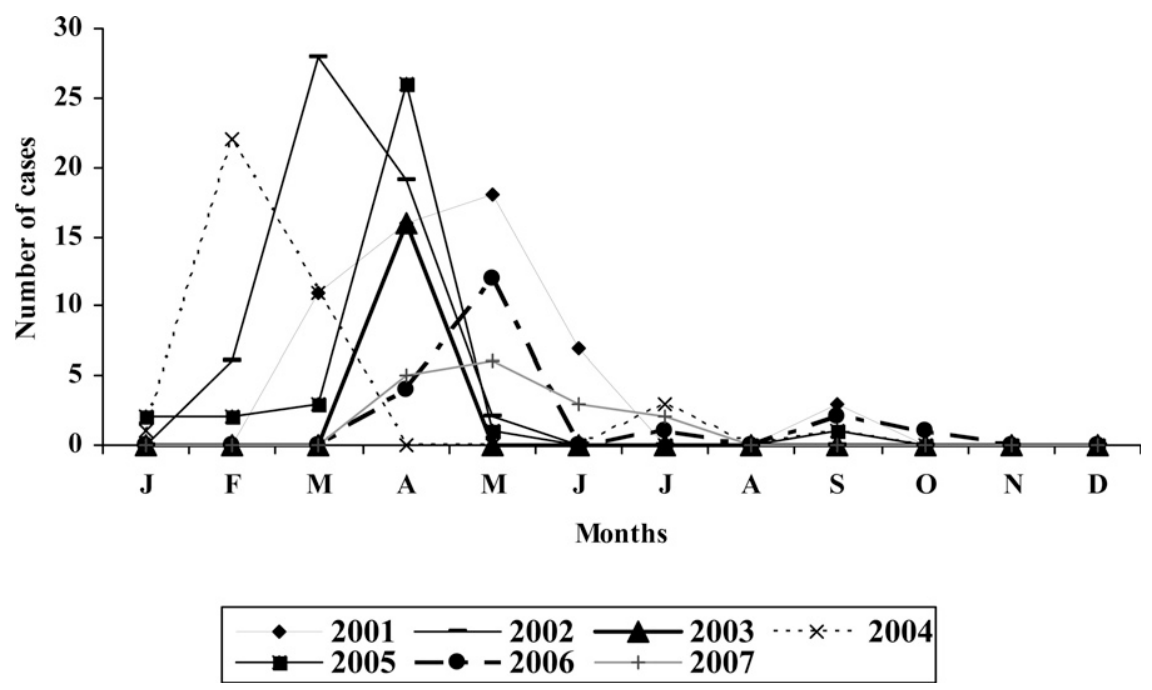

FIGURE 1. Monthly detection of influenza infections by year of study. 


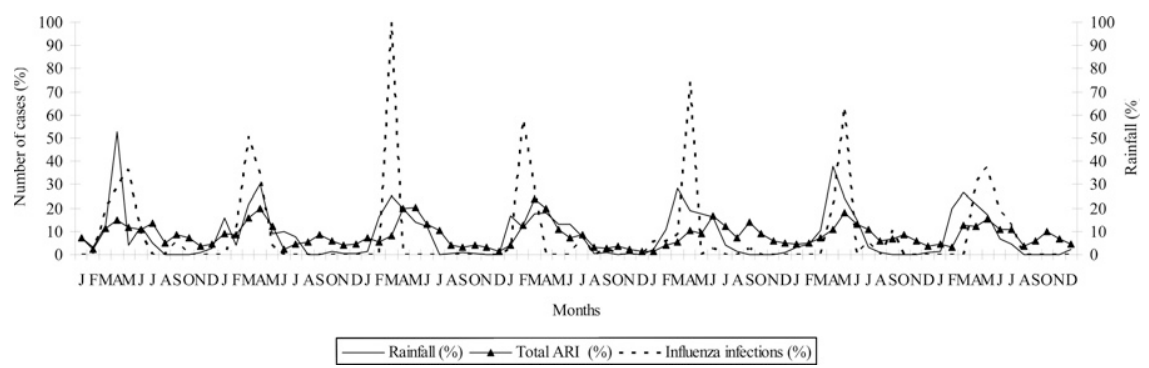

FIGURE 2. Monthly occurrence of acute respiratory infections caused by influenza viruses and rainfall in Fortaleza, Brazil, from January 2001 to December 2007.

the rainy season. It was observed that influenza seasons were shorter than rainy seasons. During the study, not once did the influenza season begin before the rainy season.

The only previous study with data about seasonality of respiratory viruses in Fortaleza, including influenza, reported an occurrence of two peaks of influenza of similar intensity in the same year. The first came during February and March, and the second in December, both associated with the occurrence of rain in the city. ${ }^{9}$ Results shown here strengthen the relation among occurrence of rainy seasons and influenza in Fortaleza already presented in that previous report. Nevertheless, the occurrence of two periods of influenza in the same year was not seen at any point during the 7 years of study. In fact, the occurrence of a second peak in 1985 can be explained by the earlier occurrence of a rainy period in December seen during some years. An ample review of occurrence of rainy periods in Fortaleza in December, from 1976 to 2007, shows this fact as rare, only observed in 1985 and 1988.

In this study, $5.5 \%$ of cases of influenza occurred in the last 6 months of the year, in July or September. September was the month with more detection of cases outside of a regular period of occurrence, with one, two, or three cases by year in 4 years of the period of study. A feasible explanation for the occurrence of cases out of regular period of influenza in months such as July or September (2001, 2004, 2005, and 2006) is the increase in the influx of tourists from other Brazilian regions. It is interesting to observe that in July, a holiday month in Brazil, Fortaleza is visited by a great number of people from other regions of the country, most of them from the southeast and south regions, to escape the lower temperatures of regular occurrence during this month in their origin regions. Because the influenza periods in these regions are from May to September (peaking from June to August), some tourists can leave their cities with manifested influenza or in incubation, representing potential transmitters for people susceptible to this infection in Fortaleza. The protection provided by natural immunity resulting from prior exposure to the influenza virus could represent a possible explanation for the lack of occurrences of a large number of influenza cases during those months. To sustain this hypothesis, it would be necessary to confirm the antigenic similarity between the circulating strains in Fortaleza in the epidemic periods and those circulating in July and September.

A recent study on influenza seasonality in Brazil showed that the earliest laboratory-confirmed cases of influenza occur in the northern region. ${ }^{20}$ Comparing our data with those presented in that study, we observed a similarity in the period of detection of the first influenza cases in the north and in this area of the northeast. Another similarity concerning influenza seasonality among these two Brazilian regions is the period of peak circulation of influenza viruses. The periodicity of one epidemic of influenza a year, in a regular pattern, seen in this study, is an aspect different from the northern region, where influenza viruses are detected from November to May, with two peaks: a major one in March and a minor one in November. ${ }^{20}$ The regular occurrence of one epidemic per year, shown here, can be a useful factor for the planning and execution of strategies for prevention of this disease.

The limited data on influenza in other northeastern states reported in short-term studies do not allow the establishment of a safe description of the pattern of influenza among states of this region, although they seem to indicate intraregional variations. ${ }^{12-14}$ Two studies in the city of Maceió presented some differences: in one, $\sim 72 \%$ of influenza infections occurred in June, whereas in the other, they were identified from March to December, with peaks in June, September, and October. ${ }^{12,14}$ In 1998, an outbreak of influenza was observed from September to November in the city of Salvador. ${ }^{13}$ Both Salvador and Maceió, along with the other five state capitals of northeast Brazil, are participants of the Brazilian Influenza Surveillance System implemented in Brazil in 2000. More consistent data on seasonal influenza viruses in the northeast region may be obtained from the publication of results of this survey.

The most common explanation for the seasonality of influenza is the variation in temperature and humidity, climatic variables that have a narrow range in Fortaleza. Recent reviews on the epidemiology of influenza showed evidence of the HopeSimpson model that suggests an influence of solar radiation in the seasonality of influenza. ${ }^{21,22}$ Vitamin D is formed in the skin by UVB radiation from the sun. It has an effect on innate immunity, stimulating the expression of potent antimicrobial peptides that play a major role in protecting the respiratory tract from infections. In some regions of temperate climate, impairment in the synthesis of vitamin $\mathrm{D}_{3}$ has been shown during the winter season, a period with reduction of hours of sunlight, ${ }^{23,24}$ The impact of rainy seasons on the reduction of the time of sunlight, UVB radiation, and, consequently, vitamin D synthesis needs to be studied in regions of tropical climate, such as Fortaleza, where rainy seasons occur regularly for short periods of 3 or 4 months, with weekly and daily variations in intensity of precipitation.

The intra- and inter-regional variations of the occurrence of influenza reported in several Brazilian studies mentioned here suggest the complexity in controlling these infections in Brazil. The results of this analysis covering 7 consecutive years of influenza surveillance at a pediatric hospital in Fortaleza contributes to a better understanding of influenza seasonality in tropical regions. 
Received September 15, 2008. Accepted for publication January 29, 2009.

Financial support: This work was supported by the Conselho Nacional de Desenvolvimento Tecnológico (CNPq) Grant 620053/2004-6 and Ministry of Health of Brazil/DECIT and Secretary of Health of Ceará.

Authors' addresses: Fernanda E. A. Moura and Anne C. B. Perdigão, Laboratório de Virologia do Departamento de Patologia e Medicina Legal, Universidade Federal do Ceará, Rua Monsenhor Furtado SN, Rodolfo Teófilo, CEP 60441-750, Fortaleza-CE, Brazil. Marilda M. Siqueira, Laboratório de Vírus Respiratórios, Instituto Oswaldo Cruz (IOC-FIOCRUZ), Av. Brasil, 4365, Manguinhos, CEP 21040360, Rio de Janeiro-RJ, Brazil.

\section{REFERENCES}

1. Shek LP, Lee BW, 2003. Epidemiology and seasonality of respiratory tract infections in the tropics. Paediatr Respir Rev 4: 104-111.

2. Beckett CG, Hosasih H, Ma'roef C, Listiyonengsih E, Elyazar IRF, Wuryadi S, Yuwone D, McArdle JL, Corwin AL, Porter KR, 2004. Influenza surveillance in Indonesia: 1999-2003. Clin Infect Dis 39: 443-449.

3. Chow A, Ma S, Ling AE, Chew SK, 2006. Influenza-associated deaths in tropical Singapore. Emerg Infect Dis 12: 114-121.

4. Doraisingham S, Goh KT, Ling AE, Yu M, 1988. Influenza surveillance in Singapore: 1972-86. Bull World Health Organ 66: $57-63$.

5. Dosseh A, Ndiaye K, Spiegel A, Sagna M, Mathiot C, 2000. Epidemiological and virological influenza survey in Dakar, Senegal: 1996-1998. Am J Trop Med Hyg 62: 639-641.

6. Nguyen HLK, Saito R, Ngiem HK, Nishikawa M, Shobugawa Y, Nguyen DC, Hoang LT, Huynh LP, Suzuki H, 2007. Epidemiology of influenza in Hanoi, Vietman, from 2001 to 2003. $J$ Infect 55: 58-63.

7. Rao BL, Banerjee K, 1993. Influenza surveillance in Pune, India. Bull World Health Organ 71: 177-181.

8. Tsai HP, Kuo PH, Liu CC, Wang JR, 2001. Respiratory viral infections among inpatients and outpatients in Taiwan from 1997 to 1999. J Clin Microbiol 39: 111-118.

9. Arruda E, Hayden FG, McAuliffe JF, de Sousa MA, Mota SB, McAuliffe MI, Geist FC, Carvalho EP, Fernandez MC, Guerrant RL, Gwaltney JM Jr, 1991. Acute respiratory viral infections in ambulatory children of urban northeast Brazil. J Infect Dis 164: 252-258.

10. Belley N, Carraro E, Perosa A, Granato C, 2007. Patterns of influenza infections among different risk groups in Brazil. Braz $J$ Infect Dis 11: 399-402.

11. Costa LF, Yorosawa J, Mantese OC, Oliveira TFM, Silveira HL, Nepomuceno LL, Moreira LS, Dyinosio G, Rossi LMG, Oliveira
RC, Ribeiro LZG, Queiroz DAO, 2006. Respiratory viruses in children younger than five years old with acute respiratory disease from 2001 to 2004 in Uberlândia, MG, Brazil. Mem Inst Oswaldo Cruz 101: 301-306.

12. Cruz MEM, Zaidan AME, Rodrigues MML, Sá JPO, Silva NM, Oliveira JF, 1999. Incidence of influenza A and B viruses among the population of Maceió-Al, Brazil. Rev Bras Anal Clin 31: 9-11.

13. Moura FEA, Borges LC, Souza LSF, Ribeiro DH, Siqueira MM, Ramos EAG, 2003. Estudo de infecções respiratórias agudas virais em crianças atendidas em um centro pediátrico em Salvador (BA). J Bras de Patol Med Laboratorial 39: 275-282.

14. Oliveira JF, de Sá JPO, Cruz MEM, 2004. Influenza virus A and B identification and monitoring in the population of Maceió. Cien Saude Colet 9: 241-246.

15. Vidal LR, Siqueira MM, Nogueira MB, Raboni SM, Pereira LA, Takahashi GR, Rotta I, Debur M do C, Dalla-Costa LM, 2008. The epidemiology and antigenic characterization of influenza viruses isolated in Curitiba, South Brazil. Mem Inst Oswaldo Cruz 103: 180-185.

16. Tsuchiya LR, Costa LM, Raboni SM, Nogueira MB, Pereira LA, Rotta I, Takahashi GR, Coelho M, Siqueira MM, 2005. Viral respiratory infection in Curitiba, Southern Brazil. J Infection 51: 401-407.

17. Moura FEA, Nunes IF, Junior GBS, Siquiera MM, 2006. Respiratory syncytial virus infections in Northeastern Brazil: seasonal trends and general aspects. Am J Trop Med Hyg 74: $165-167$.

18. Fé MM, Monteiro AJ, Moura FE, 2008. Parainfluenza virus infections in a tropical city: clinical and epidemiological aspects. Braz J Infect Dis 12: 192-197.

19. Viboud C, Boëlle PY, Pakdaman K, Carrat F, Valleron AI, Flahaut A, 2004. Influenza epidemics in the United States, France, and Australia, 1972-1997. Emerg Infect Dis 10: 32-39.

20. Alonso WJ, Viboud C, Simonsen L, Hirano EW, Daufenbach LZ, Miller MA, 2007. Seasonality of influenza in Brazil: a traviling wave from the Amazon to the Subtropics. Am J Epidemiol 165: $1434-1442$

21. Cannell JJ, Zasloff M, Garland CF, Scragg R, Giovannucci E, 2008. On the epidemiology of influenza. Virol J 5: 29-40.

22. Cannell JJ, Vieth R, Umhau JC, Holick MF, Grant WR, Madronich S, Garland CF, Giovannucci E, 2006. Epidemic influenza and vitamin D. Epidemiol Infect 134: 1129-1140.

23. Hirani V, Primatesta P, 2005. Vitamin D concentrations among people aged 65 years and over living in private households and institutions in England: population survey. Age Ageing 34: 485-491.

24. Weeb AR, Kline L, Holick MF, 1988. Influence of season and latitude on the cutaneous synthesis of vitamin D3: exposure to winter sunlight in Boston and Edmonton will not promote vitamin D3 in human skin. J Clin Endocrinol Metab 67: 373-378. 